Vol 13, Issue 2, 2020

\title{
ESLICARBAZEPINE AND MEMORY IMPAIRMENT IN TEMPORAL LOBE EPILEPSY: A STUDY ON THE ATTENUATING EFFECT OF NEFIRACETAM
}

\author{
BIPUL RAY, KAMSAGARA LINGANNA KRISHNA* \\ Department of Pharmacology, JSS College of Pharmacy, JSS Academy of Higher Education and Research, Mysore, Karnataka, India. \\ Email: klkrishna@jssuni.edu.in
}

Received: 28 August 2019, Revised and Accepted: 11 December 2019

\section{ABSTRACT}

Objectives: The objectives of the present investigation were to evaluate the memory impairment (MI) activity of eslicarbazepine (ESL) in temporal lobe epilepsy (TLE) at a normal and reduced dose, to evaluate the possible protective effect of nefiracetam (NEF) on MI induced by ESL at a normal and reduced dose, and to evaluate the antiepileptic activity of ESL on TLE in the presence and absence of NEF.

Methods: MI activity was evaluated by Barnes maze (BM) on lithium-pilocarpine-induced TLE in Wistar albino rats. Rats were trained by releasing from the portable start-up box after keeping sometimes inside, to find the fixed dark escape hole of BM. Mild aversive light overhead was used to motivate the finding. Animals failed to do so were guided manually. Trained animals were taken for the study and checked the escape latency time (ELT) and the error scores (error entry). The treatment was given for 1 month and MI activity was measured on every $7^{\text {th }}$ day and antiepileptic activity on every $8^{\text {th }}$ day. Phenytoin was used as standard antiepileptic drug (AED) to compare the MI extent of ESL.

Results: ESL-treated group animals had shown increased ELT and error scores, on comparison with control group, implying the MI as a result treatment of the AED ESL. MI was dose dependent and shown decreased MI in animals treated with half dose of ESL. When NEF was administered with the ESL significantly decreased the MI as well as showed potent anticonvulsant activity when compared to control and ESL alone treated group. The levels of acetylcholinesterase (AChE) in ESL group were observed to be increased against control group. Cotreatment of NEF results in decreased levels of AChE on comparison with control and the group treated with ESL.

Conclusion: The reduced dose of ESL and NEF combination was found to have synergized the protecting effect against MI compared to normal ESL and NEF group without altering anticonvulsant activity. However, further studies are required to elicit detailed protective activity of NEF on MI induced by ESL.

Keywords: Eslicarbazepine, Temporal lobe epilepsy, Memory impairment, Lithium-pilocarpine model, Nefiracetam.

(C) 2020 The Authors. Published by Innovare Academic Sciences Pvt Ltd. This is an open access article under the CC BY license (http://creativecommons. org/licenses/by/4. 0/) DOI: http://dx.doi.org/10.22159/ajpcr.2020.v13i2.35511

\section{INTRODUCTION}

Epilepsy is a neurological disorder where the recurrent seizure occurs due to the abnormal electrical firing [1-5]. The main cause of epilepsy is not cleared known although some may develop epilepsy due to brain injury, stroke, tumor, drugs, genetic mutations, etc. [6]. Memory impairment (MI) is one of the key complications associated with epilepsy and its treatment by antiepileptic drugs (AEDs). The abnormal functions of the neurotransmitter of the brain may cause stress, fatigue with in brain that causes a lapse in memory. Moreover, temporal lobe deals with the memory storage and encoding $[7,8]$. The antiepileptic therapy induces MI, especially in the case of temporal lobe epilepsy (TLE) $[9,10]$ is well reported. At high-dose sedation, unsteadiness and slurring of speech have been observed. Other side effects include nausea, rash, dysplasia, and MI. There is a need for minimizing the MI induced by epilepsy etiology and worsen condition by antiepileptic treatment. Based on the above facts, the present study is designed to evaluate the MI induced by eslicarbazepine (ESL) in lithium-pilocarpine-induced TLE in Wistar albino rats.

\section{METHODS}

\section{Animals}

Wister rats of either sex (200-250 g) were acquired from Biogen Laboratory, Bengaluru. The experimental work was carried out during the year 2016-2017. The animals were encased in cages made of polypropylene at around $23-27^{\circ} \mathrm{C}$ in light-dark cycle. The animals were provided food pellet and water ad libitum. A 7-day's acclimatization period was allotted before the experiments to start. Groups of eight rats were used for the experiments. The experimental protocol was approved (Institutional Animal Ethics Committee [IAEC] No. 201/2016) by the IAEC of JSS College of Pharmacy, Mysore, Karnataka.

\section{Drugs procurement}

ESL and diazepam were procured from JSS Hospital, Mysore, and pilocarpine, lithium chloride, and nefiracetam (NEF) were procured from Sigma-Aldrich.

\section{In vivo activities}

Lithium-pilocarpine model [11-13]

Pilocarpine, a muscarinic agonist, causing the imbalance between excitatory and inhibitory transmission through the M1 activation resulting in the generation of status epilepticus development of spontaneous recurrent seizer [14]. Pilocarpine (30 mg/kg i.p.) was administered in combination with lithium chloride ( $3 \mathrm{mmol}$ s.c), $24 \mathrm{~h}$ before the pilocarpine induction to reduce its high dose and its mortality. The grouping and animals, treatment, and evaluation were done, as shown in Table 1 and Fig. 1.

\section{Antiepileptic activity [15,16]}

By Racine scoring method, antiepileptic activity was scored in TLE rats. Diazepam of about $10 \mathrm{mg} / \mathrm{kg}$ was given intraperitoneally for the control group animals to halt the TLE at the Stage 4 to conserve the life of animal. 
Barnes maze (BM) [17-19]

Visualized spatial learning and memory were estimated by employing the BM which has 18 holes that are uniformly separated along the circumference and made up of round platform placed at elevated level. An aversive bright light was used to encourage the rats to make entry into the escape box beneath the hole (Fig. 1). Animals were given visual clues kept distally around the maze surroundings to determine the special place of the hole to escape. The errors, such as head deflections and nose protrusions above any hole, where it cannot escape and also latency, the time that animal takes to determine the escape hole were measured.

Estimation of brain acetylcholinesterase activity [20]

Acetylcholinesterase activity was measured from the brain hippocampus region by Ellman et al. [20] method.

\section{RESULTS}

The animals were treated in different groups for 29 days, as shown in Table 1. It was observed that when ESL ( $40 \mathrm{mg} / \mathrm{kg}$ p.o.) administration to rats with pilocarpine-induced convulsions, there was a significant increase in escape latency time (ELT) $(179.80 \pm 0.25 \mathrm{~s})$ when compared to the normal group ELT $(17.83 \pm 1.90 \mathrm{~s})$ in the BM assessment. Impairment of ESL was found to be almost similar to phenytoin (PHT), a standard drug used in antiepileptic therapy. The reduced

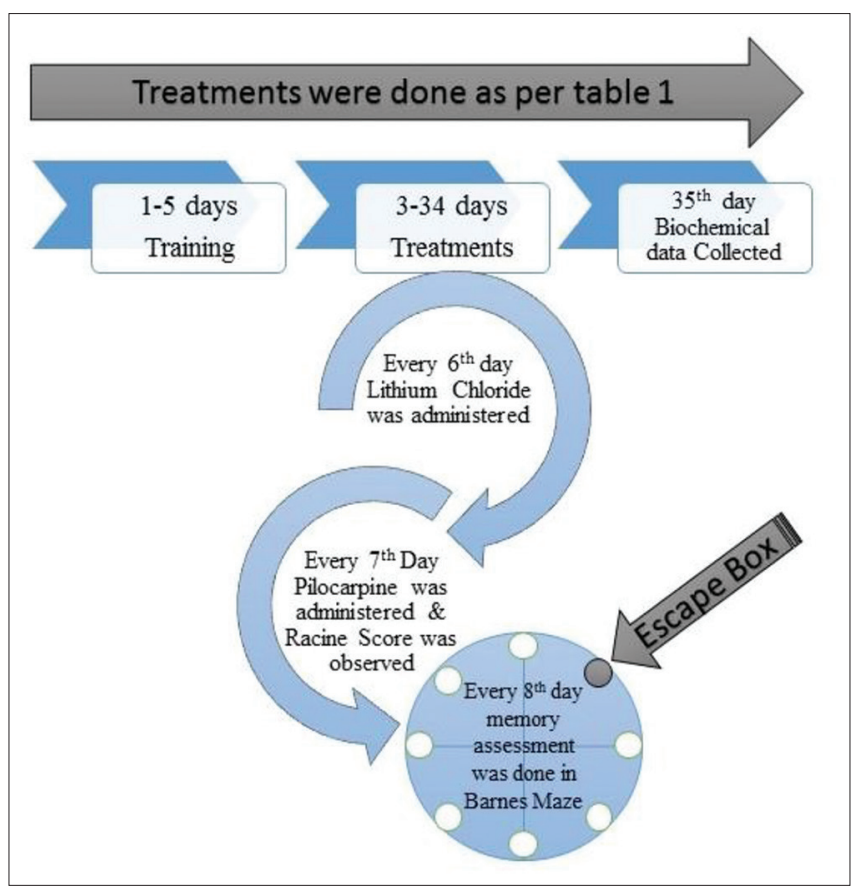

Fig. 1: Depiction of the study protocol

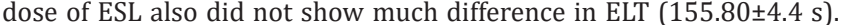
Administration of ESL half dose of $20 \mathrm{mg} / \mathrm{kg}$ along with NEF (10 mg/kg) with pilocarpine-induced convulsions resulted in a significant decrease in ELT of $(36.10 \pm 2.60 \mathrm{~s})$ when compared to the PHT $(163.10 \pm 1.50 \mathrm{~s})$ and control group $(134.80 \pm 3.50 \mathrm{~s})$.

In terms of error scores of BMs, in the same pilocarpine-induced TLE animals, there was a significant increase in error scores in ESL $(40 \mathrm{mg} / \mathrm{kg})$ treatment $(27.44 \pm 0.69)$ when compared to the normal $(0.31 \pm 0.41)$ and control group $(19.11 \pm 0.69)$. The reduced dose of ESL $(20 \mathrm{mg} / \mathrm{kg})$ alone also shown dose-dependent decrease in error score $(15.44 \pm 1.19)$ compared to ESL normal dose. It was observed that administration of NEF $(10 \mathrm{mg} / \mathrm{kg})$ along with reduced ESL $(20 \mathrm{mg} / \mathrm{kg})$ in pilocarpine-induced convulsions resulted in decrease in error score $(2.14 \pm 0.80)$ when compared to the ESL $(27.44 \pm 0.69)$, PHT

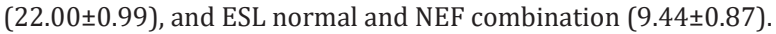

The anticonvulsant effect was measured to be effective if the Racine score becomes lesser in a scale of $0-5$. The control group was given pilocarpine (30 mg/kg i.p.) with the pre-treatment of lithium chloride ( $3 \mathrm{mmol}$ s.c), Racine score was observed, before reaching to 5 scoring, the control group was treated with diazepam $(10 \mathrm{mg} / \mathrm{kg}$ i.p.) to stop the mortality. The ESL treatment groups Racine score $(0.37 \pm 0.50)$ was found to be significant compared to control group (4.25 \pm 0.31$)$. The reduced dose of ESL $(20 \mathrm{mg} / \mathrm{kg})$ and NEF $(10 \mathrm{mg} / \mathrm{kg})$ was found to have synergized the antiepileptic activity by decreasing the Racine score $(0.00 \pm 0.00)$ compared to ESL and NEF normal combination group $(1.00 \pm 0.20)$.

The acetylcholinesterase (AChE) levels were measured by the hippocampus region of the rat's brain. This was observed more in the PHT $(7.80 \pm 0.13)$ and ESL $(8.38 \pm 0.09)$ treating group animal. The levels were observed to be decreased with the reduce ESL (3.92 \pm 0.17$)$ dose. In the reduced ESL and NEF combination, dose $(2.19 \pm 0.10)$ was found to be more potent than the normal combination of ESL and NEF $(3.20 \pm 0.11)$.

\section{DISCUSSION}

The temporal lobe of the brain plays a crucial role in the formation of memory and storage. Any abnormality in this lobe, especially the TLE, can cause the memory dysfunction $[9,21]$. Moreover, there are various studies reported the worsening of MI caused by the AED therapy $[22,23]$. Our study was hypothesized, whether coadministration of nootropic drug, NEF along with the ESL can overcome the MI caused due to AED therapy.

The lithium-pilocarpine model of TLE resembles the human TLE [22]. In case of animal model, the TLE was evaluated by the Racine scores, lesser the scores better the potency of the drug. The cognitive functions were assessed by BM $[17,24]$. Escape latency and error score were assessed in BM, as shown in Figs. 2 and 3, the ESL-induced groups showed more MI than the control group. On the other hand, ESL reduced dose group was seen to have less MI (Figs. 2 and 3), but it did not show

Table 1: Groupings, treatment, and assessment

\begin{tabular}{lll}
\hline Groupings & Treatment & Assessments \\
\hline Normal & Vehicle $(0.5 \%$ Na-CMC) p.o. daily for 29 days & Every $7^{\text {th }}$ day antiepileptic activity and every $8^{\text {th }}$ day \\
Control & Vehicle p.o. daily for 29 days+Pilocarpine on every $7^{\text {th }}$ day & cognitive functions were assessed for the entire study \\
Phenytoin (PHT) & $25 \mathrm{mg} / \mathrm{kg}$ p.o. daily for 29 days+Pilocarpine on every $7^{\text {th }}$ day & period \\
ESL ND & $40 \mathrm{mg} / \mathrm{kg}$ p.o. daily for 29 days+Pilocarpine on every $7^{\text {th }}$ day & Estimation of brain acetylcholinesterase level at the end \\
ESL RD & $20 \mathrm{mg} / \mathrm{kg}$ p.o. daily for 29 days+Pilocarpine on every $7^{\text {th }}$ day & of treatment period \\
ESL ND+NEF & $40 \mathrm{mg} / \mathrm{kg}$ p.o. and NEF $(10 \mathrm{mg} / \mathrm{kg}$ p.o.) for 29 days & \\
& Pilocarpine on every $7^{\text {th }}$ day & \\
ESL RD+NEF & $20 \mathrm{mg} / \mathrm{kg}$ p.o. and NEF $(10 \mathrm{mg} / \mathrm{kg}$ p.o.) for 29 days + & \\
& Pilocarpine on every $7^{\text {th }}$ day & \\
NEF & $10 \mathrm{mg} / \mathrm{kg}$ p.o. for 29 days+Pilocarpine on every $7^{\text {th }}$ day & \\
\hline
\end{tabular}

ESL: Eslicarbazepine, ND: Normal dose, RD: Reduced dose, NEF: Nefiracetam 


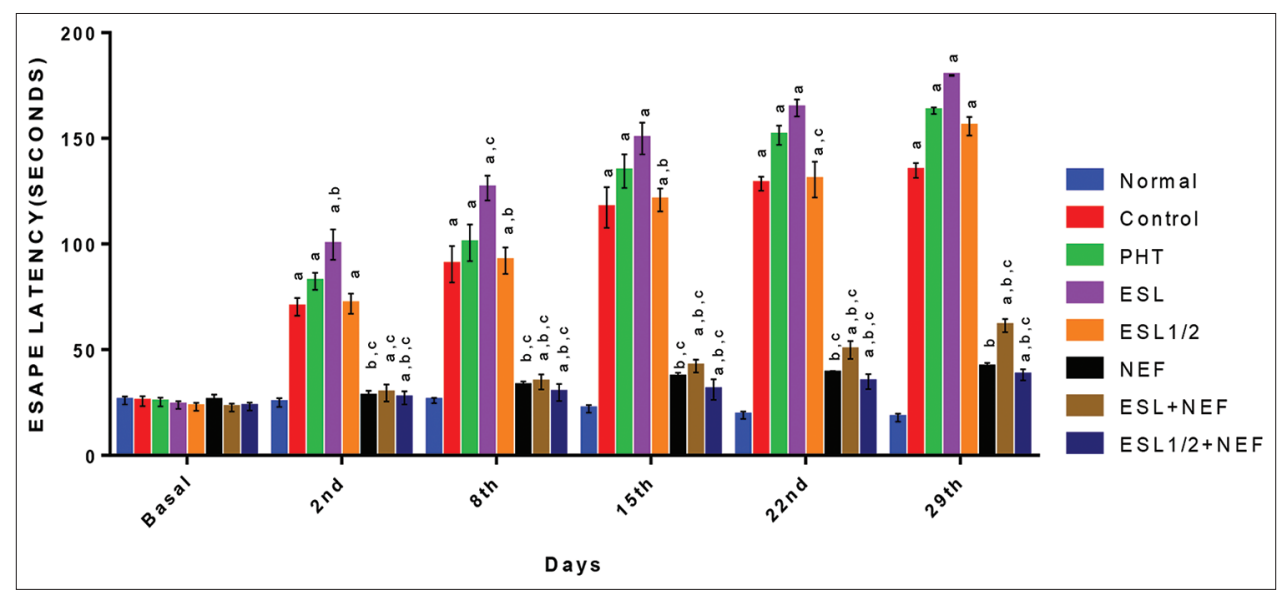

Fig. 2: Memory impairment activity of eslicarbazepine (ESL) and its correction by nefiracetam on temporal lobe epilepsy-induced epileptic rats (escape latency). Data are expressed as mean \pm standard error of the mean, $n=8, a-$ significant when compared to control ( $p \leq 0.05), b$ - significant when compared to phenytoin ( $p \leq 0.05), c$ - significant when compared to ESL ( $\leq \leq 0.05)$

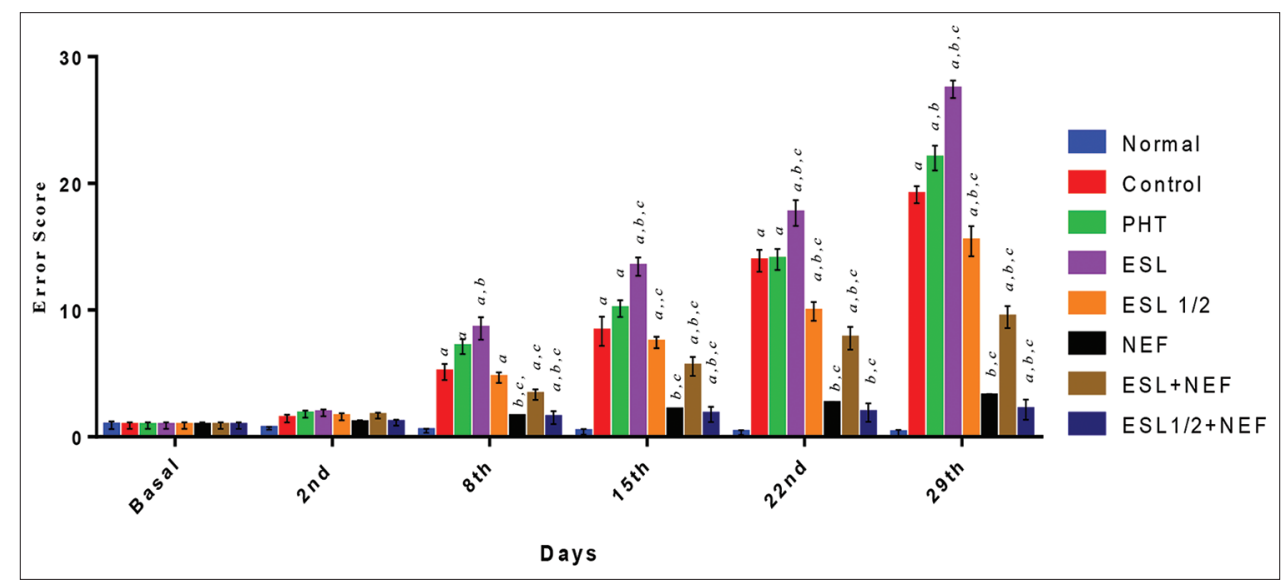

Fig. 3: Memory impairment activity of eslicarbazepine (ESL) and its correction by nefiracetam on temporal lobe epilepsy-induced epileptic rats (error scores). Data are expressed as mean \pm standard error of the mean, $n=8, a-$ significant when compared to control $(p \leq 0.05), b-$ significant when compared to phenytoin ( $p \leq 0.05), c-$ significant when compared to ESL ( $p \leq 0.05)$

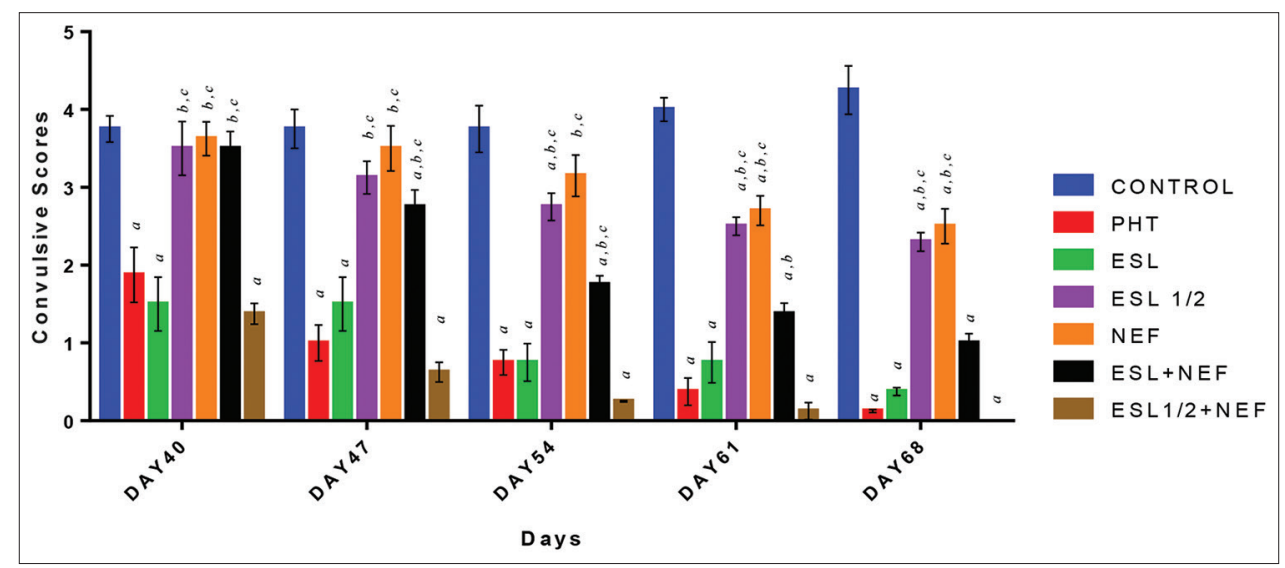

Fig. 4: Antiepileptic activity of eslicarbazepine (ESL) and nefiracetam alone and in combination on temporal lobe epilepsy-induced epileptic rats (convulsive scores). Data are expressed as mean \pm standard error of the mean, $\mathbf{n = 8}$, a - significant when compared to control ( $p \leq 0.05), b$ - significant when compared to phenytoin ( $p \leq 0.05), c$ - significant when compared to ESL $(p \leq 0.05)$

potent antiepileptic activity than ESL normal dose. The result suggested that the treatment with the ESL in epileptic condition increases in the declines of the cognitive function with the higher doses. It was even observed that the MI of ESL was dose dependent.
In the combination of ESL and NEF, dose reduces the MI significantly than ESL but not as compared to ESL reduce dose and NEF combination. ESL reduced dose and NEF combination was shown to have a synergistic effect to reduce MI without altering its antiepileptic activity (Figs. 4 and 5). 


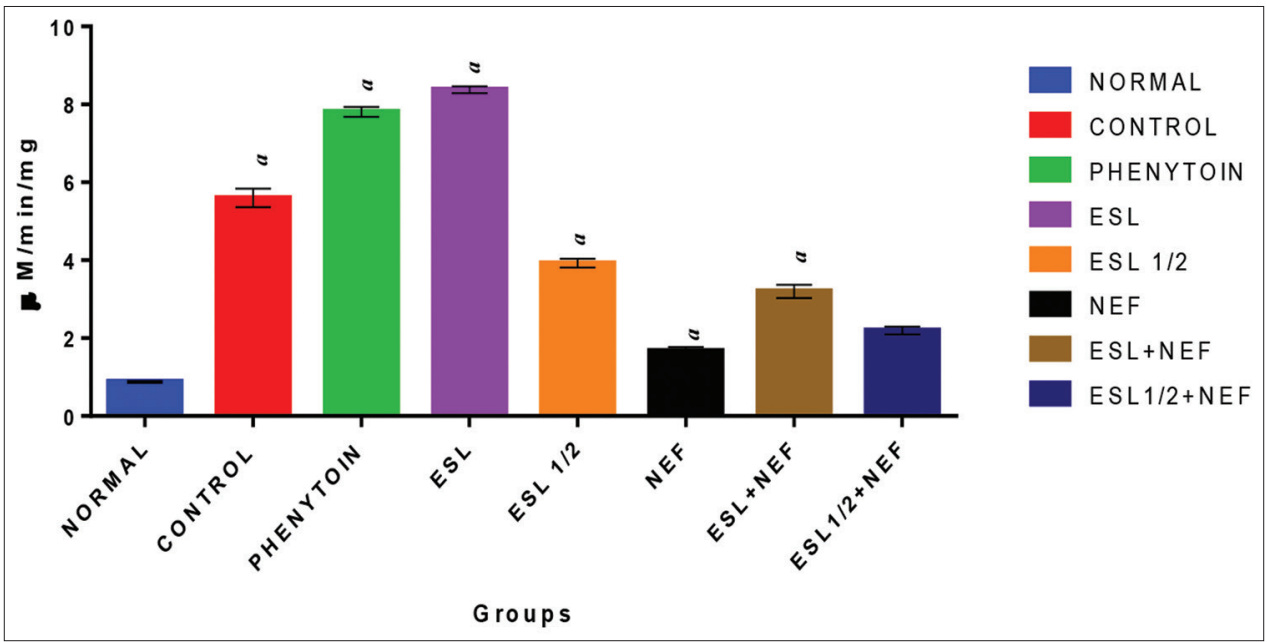

Fig. 5: Memory impairment activity of eslicarbazepine (ESL) and its correction by nefiracetam on temporal lobe epilepsy-induced epileptic rats (acetylcholinesterase levels). Data are expressed as mean \pm standard error of the mean, $n=8, a-$ significant when compared to control $(p \leq 0.05), b-$ significant when compared to phenytoin $(p \leq 0.05), c$ - significant when compared to ESL ( $\leq \leq 0.05)$

The AChE data also supported that the combination of reducing dose of ESL and NEF has synergized the effect to reduce the MI compared to normal dose combination [22].

\section{CONCLUSION}

The major drawback of antiepileptic treatment is MI notably in epilepsy of temporal lobe because temporal lobe of brain is the major part which deals with the memory encoding and storage. The objective of the present study in brief was treating epilepsy by reducing the MI induced by ESL. The MI was seen more in ESL-treated group compared to control as AEDs aggravate more MI. The ESL half doses also reduce the MI but not as compared to control group. When given NEF, a nootropic agent combined with ESL reduces MI but not as in case on comparison with ESL reduced dose and NEF combination. The combination of ESL reduced dose and NEF was seen to have a synergistic effect to reduce the $\mathrm{V}$ without altering the antiepileptic effect in lithium-pilocarpineinduced TLE in rats model.

\section{ACKNOWLEDGMENT}

The authors sincerely thank Principal, JSS College of Pharmacy, Mysore, for his support and encouragement. Our gratitude goes to JSS Academy of Higher Education and Research, Mysore, for providing all the necessary facilities.

\section{AUTHORS' CONTRIBUTIONS}

Mr. Bipul Ray - The present research work was the M. Pharm dissertation of Mr. Bipul Ray Dr. K L Krishna - Research guide for the M. Pharm Dissertation.

\section{CONFLICTS OF INTEREST}

The authors assert to have no conflicts of interest.

\section{REFERENCES}

1. Chizhov AV, Amakhin DV, Zaitsev AV. Computational model of interictal discharges triggered by interneurons. PLoS One 2017;12:e0185752.

2. Lee HF, Chi CS. Febrile infection-related epilepsy syndrome (FIRES): Therapeutic complications, long-term neurological and neuroimaging follow-up. Seizure 2018;56:53-9.

3. Tara E, Vitenzon A, Hess E, Khodakhah K. Aberrant cerebellar Purkinje cell activity as the cause of motor attacks in a mouse model of episodic ataxia Type 2. Dis Model Mech 2018;11:dmm034181.

4. Budikayanti A, Chaliana C, Louisa M, Setiabudy R. Development and validation of carbamazepine plasma concentrations measurement and its application on epilepsy patients. Int J Pharm Pharm Sci 2017;9:87-91.
5. VijayakumarAE,Vinay M, Seethalakshmi.Methanolic extract of Bacopa Monniera reduce developmen of tolerance to antiepileptic effect of phenobarbitone in mice. Int J Pharm Pharm Sci 2015;7:256-9.

6. Herzog AG. Catamenial epilepsy: Update on prevalence, pathophysiology and treatment from the findings of the NIH progesterone treatment trial. Seizure 2015;28:18-25.

7. Audrain S, Barnett AJ, McAndrews MP. Language network measures at rest indicate individual differences in naming decline after anterior temporal lobe resection. Hum Brain Mapp 2018;39:4404-19.

8. Stevenson RF, Zheng J, Mnatsakanyan L, Vadera S, Knight RT, Lin JJ, et al. Hippocampal CA1 gamma power predicts the precision of spatial memory judgments. Proc Natl Acad Sci U S A 2018;115:10148-53.

9. Tramoni-Negre E, Lambert I, Bartolomei F, Felician O. Long-term memory deficits in temporal lobe epilepsy. Rev Neurol (Paris) 2017;173:490-7.

10. de Kinderen RJ, Evers SM, Rinkens R, Postulart D, Vader CI, Majoie MH, et al. Side-effects of antiepileptic drugs: The economic burden. Seizure 2014;23:184-90.

11. Curia G, Longo D, Biagini G, Jones RS, Avoli M. The pilocarpine model of temporal lobe epilepsy. J Neurosci Methods 2008;172:143-57.

12. Brandt C, Bankstahl M, Töllner K, Klee R, Löscher W. The pilocarpine model of temporal lobe epilepsy: Marked intrastrain differences in female sprague-Dawley rats and the effect of estrous cycle. Epilepsy Behav 2016;61:141-52.

13. García-García L, Shiha AA, de la Rosa RF, Delgado M, Silván Á, Bascuñana $P$, et al. Metyrapone prevents brain damage induced by status epilepticus in the rat lithium-pilocarpine model. Neuropharmacology 2017;123:261-73.

14. Lévesque M, Avoli M, Bernard C. Animal models of temporal lobe epilepsy following systemic chemoconvulsant administration. J Neurosci Methods 2016;260:45-52.

15. Racine RJ. Modification of seizure activity by electrical stimulation. II. Motor seizure. Electroencephalogr Clin Neurophysiol 1972;32:281-94.

16. Derera ID, Delisle BP, Smith BN. Functional neuroplasticity in the nucleus tractus solitarius and increased risk of sudden death in mice with acquired temporal lobe epilepsy. eNeuro 2017;4:ENEURO.0319-17.2017.

17. Rosenfeld CS, Ferguson SA. Barnes maze testing strategies with small and large rodent models. J Vis Exp 2014;84:e51194.

18. O'Leary TP, Brown RE. Optimization of apparatus design and behavioral measures for the assessment of visuo-spatial learning and memory of mice on the Barnes maze. Learn Mem 2013;20:85-96.

19. Attar A, Liu T, Chan WT, Hayes J, Nejad M, Lei K, et al. A shortened Barnes maze protocol reveals memory deficits at 4-months of age in the triple-transgenic mouse model of Alzheimer's disease. PLoS One 2013;8:e80355.

20. Ellman GL, Courtney KD, Andres V Jr., Feather-Stone RM. A new and rapid colorimetric determination of acetylcholinesterase activity. Biochem Pharmacol 1961;7:88-95.

21. Zhao F, Kang H, You L, Rastogi P, Venkatesh D, Chandra M. Neuropsychological deficits in temporal lobe epilepsy: A comprehensive review. Ann Indian Acad Neurol 2014;17:374-82. 
22. Mohan AJ, Krishna KL. Memory impairment allied to temporal lobe epilepsy and its deterioration by phenytoin: A highlight on ameliorative effects of levetiracetam in mouse model. Int J Epilepsy 2018;5:19-27.

23. Mula M, Trimble MR. Antiepileptic drug-induced cognitive adverse effects: Potential mechanisms and contributing factors. CNS Drugs
2009;23:121-37.

24. Gawel K, Gibula E, Marszalek-Grabska M, Filarowska J, Kotlinska JH. Assessment of spatial learning and memory in the Barnes maze task in rodents-methodological consideration. Naunyn Schmiedebergs Arch Pharmacol 2019;392:1-18 